\title{
FDG-PET/CT for pre-operative staging and prognostic stratification of patients with high-grade prostate cancer at biopsy
}

Jean-Mathieu Beauregard ${ }^{1,2+}$, Annie-Claude Blouin ${ }^{3,4+}$, Vincent Fradet ${ }^{3,4}$, André Caron ${ }^{3,4}$, Yves Fradet ${ }^{3,4}$, Claude Lemay ${ }^{5}$, Louis Lacombe ${ }^{3,4}$, Thierry Dujardin ${ }^{3,4}$, Rabi Tiguert ${ }^{3,4}$, Goran Rimac ${ }^{3,4}$, Frédérick Bouchard ${ }^{3,4}$ and Frédéric Pouliot ${ }^{3,4^{*}}$

\begin{abstract}
Background: The role of ${ }^{18}$ F-fluorodeoxyglucose positron emission tomography/computed tomography (FDG-PET/CT) in prostate cancer ( $\mathrm{PCa}$ ) has not been well defined yet. Because high-grade PCa tends to exhibit increased glycolytic rate, FDG-PET/CT could be useful in this setting. The aim of this study was to assess the value of FDG-PET/CT for pre-operative staging and prognostic stratification of patients with high-grade PCa at biopsy.

Methods: Fifty-four patients with a Gleason sum $\geq 8$ PCa at biopsy underwent FDG-PET/CT as part of the staging workup. Thirty-nine patients underwent radical prostatectomy (RP) and pelvic lymph node (LN) dissection, 2 underwent LN dissection only, and 13 underwent non-surgical treatments. FDG-PET/CT findings from clinical reports, blinded reading and quantitative analysis were correlated with clinico-pathological characteristics at RP.

Results: Suspicious foci of increased FDG uptake were found in the prostate, LNs and bones in 44,13 and $6 \%$ of patients, respectively. Higher clinical stage, post-RP Gleason sum and pattern, and percentage of cancer involvement within the prostate were significantly associated with the presence of intraprostatic FDG uptake (IPFU) $(P<0.05$ in all cases). Patients without IPFU who underwent RP were downgraded to Gleason $\leq 7$ in $84.6 \%$ of cases, as compared to $30.8 \%$ when IPFU was reported $(P=0.003)$. Qualitative and quantitative IPFU were significantly positively correlated with post-RP Gleason pattern and sum, and pathological T stage. Absence and presence of IPFU were associated with a median 5-year cancer-free survival probability of 70.2 and $26.9 \%(P=0.0097)$, respectively, using the CAPRA-S prognostic tool.

Conclusion: These results suggest that, among patients with a high-grade PCa at biopsy, FDG-PET/CT could improve pre-treatment prognostic stratification by predicting primary PCa pathological grade and survival probability following RP.
\end{abstract}

Keywords: FDG-PET/CT, High-grade, Prognostic stratification, Prostate cancer, Staging

\section{Background}

Staging and prognostication of primary prostate cancer $(\mathrm{PCa})$ is of prime importance, especially for aggressive $\mathrm{PCa}$, for which failure rate to local therapy is high [1]. Over the last decades, a number of clinical tools such as

\footnotetext{
* Correspondence: frederic.pouliot@crchuq.ulaval.ca

${ }^{\dagger}$ Equal contributors

${ }^{3}$ Division of Urology, Department of Surgery and Cancer Research Center, Université Laval, Quebec City, Canada

${ }^{4}$ Division of Urology, Department of Surgery and Oncology Axis of CHU de Québec Research Center, CHU de Québec, Quebec City, Canada

Full list of author information is available at the end of the article
}

nomograms and imaging technologies have gained wide acceptance, but their accuracy for pre-treatment staging and prognostication is limited.

Molecular imaging with positron emission tomography/computed tomography (PET/CT) can detect molecular changes within cancer cells before morphological changes become apparent on conventional anatomical imaging such as standalone $\mathrm{CT}$ or magnetic resonance imaging [2]. The most widely used PET/CT application is the assessment of glucose metabolism using the glucose analogue ${ }^{18}$ F-fluorodeoxyglucose (FDG) [3]. FDG

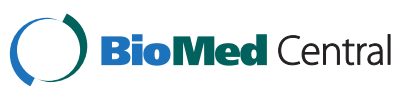


uptake has been shown to correlate with tumour grade and aggressiveness for many cancers, including metastatic PCa [4,5]. Nevertheless, FDG-PET/CT is not routinely performed in PCa patients, as low FDG accumulation in the majority of PCa tumours, which tend to be indolent, has been perceived as a major limitation. Also, early studies often included small and/or heterogeneous cohorts of patients with respect to clinical stage and grade of the disease, and many results were obtained using standalone PET rather than PET/CT $[3,6,7]$. More recent clinical data have shown that FDG uptake tends to increase in more aggressive $\mathrm{PCa}$, either recurrent or metastatic $[4,5,8,9]$. For instance, Beauregard et al. found a detection rate of $69 \%$ for FDG-PET/CT, compared to $13 \%$ for conventional imaging (CT and bone scan) in 16 patients evaluated for staging or restaging of non-low-risk PCa [9]. Furthermore, overexpression of glucose transporters has been evidenced in high-Gleason score PCa $[10,11]$. We therefore hypothesized that FDG-PET/CT might be useful in the initial staging and prognostication of high-grade $\mathrm{PCa}$ (Gleason $\geq 8$ ) at biopsy.

\section{Methods}

\section{Patients}

Fifty-four patients newly diagnosed with a Gleason sum $\geq 8$ adenocarcinoma of the prostate at 12-core transrectal ultrasound-guided prostate biopsy were referred for a staging FDG-PET/CT at CHU de Québec, in addition to whole-body bone scan. Patients with a prior history of malignancy within 5 years were excluded. Baseline patient characteristics are summarized in Table 1 . The institutional Ethics committee approved this retrospective study.

\section{FDG-PET/CT}

Patients were asked to fast for 6 hours and their glycaemia was checked. FDG-PET/CT was performed approximately 75 minutes after the administration of $300-500 \mathrm{MBq}$ FDG, with oral contrast, from base of skull to upper thighs, on a Biograph 6 PET/CT system (Siemens Healthcare, Erlangen, Germany).

Clinical reporting of FDG-PET/CT was performed by one of three attending nuclear medicine physicians, using a Syngo MI workstation (Siemens Healthcare). The presence or absence of suspicious FDG uptake in the prostate (intraprostatic FDG uptake or IPFU), regional lymph nodes (LNs) and distant sites was extracted from the clinical reports. More than 8 months after the last patient accrual, one nuclear medicine physician (J.M.B.) reviewed the FDG-PET/CT images blinded to the clinical PET/CT report and any clinical data other than the implicit knowledge that all patients had a biopsy-proven highgrade $\mathrm{PCa}$, and scored the IPFU as follows: 0) no focal uptake above background; focal uptake of 1) mild - less than liver, 2) moderate - similar to liver, 3) intense - more than liver, or 4) very intense level - much more than liver. Scores 0 and 1 were considered negative, while scores 2 to 4 were considered positive for significant IPFU. The prostatic maximum standardized uptake value for body weight $\left(\mathrm{SUV}_{\text {max }}\right)$ was measured independently, with caution to exclude any urinary activity. $\mathrm{SUV}_{\max }<4.0$ was considered negative for IPFU and $\geq 4.0$, positive. In one patient, the

Table 1 Patient baseline characteristics

\begin{tabular}{|c|c|c|c|c|c|c|c|c|}
\hline & & \multicolumn{2}{|c|}{ Surgical patients $(n=41)$} & \multicolumn{2}{|c|}{ Non-surgical patients $(n=13)$} & \multicolumn{2}{|c|}{ All patients $(n=54)$} & \multirow[t]{2}{*}{$P$-value } \\
\hline & & No. (\%) & Median (range) & No. (\%) & Median (range) & No. (\%) & Median (range) & \\
\hline Age, years & & & $67.5(48.7-75.5)$ & & $65.8(50.0-82.6)$ & & $66.3(48.6-82.6)$ & 0.77 \\
\hline \multirow[t]{2}{*}{ Biopsy Gleason score* } & 8 & $32(78.0)$ & & $4(30.8)$ & & $36(66.7)$ & & 0.005 \\
\hline & 9 & $9(22.0)$ & & $9(69.2)$ & & $18(33.3)$ & & \\
\hline \multirow[t]{4}{*}{ Pretreatment PSA (ng/ml) } & & & $7.0(1.7-57.0)$ & & $15.9(2.9-263.0)$ & & $7.6(1.67-263.0)$ & 0.006 \\
\hline & $<10.0$ & $31(75.6)$ & & $5(38.5)$ & & $36(66.7)$ & & \\
\hline & 10.0-19.9 & $9(22.0)$ & & $3(23.1)$ & & $12(22.2)$ & & \\
\hline & $\geq 20.0$ & $1(2.4)$ & & $5(38.5)$ & & $6(11.1)$ & & \\
\hline \multirow[t]{5}{*}{ Clinical T stage $^{\dagger}$} & cT1 & $15(36.6)$ & & $3(23.1)$ & & $18(33.3)$ & & 0.006 \\
\hline & cT2 & $14(34.1)$ & & $2(15.4)$ & & $16(29.6)$ & & \\
\hline & cT3 & $6(14.6)$ & & $5(38.5)$ & & $11(20.4)$ & & \\
\hline & cT4 & $0(0.0)$ & & $3(23.1)$ & & $3(5.6)$ & & \\
\hline & $\mathrm{n} / \mathrm{a}$ & $6(14.6)$ & & $0(0.0)$ & & $6(11.1)$ & & \\
\hline
\end{tabular}

PSA = prostate-specific antigen; $\mathrm{n} / \mathrm{a}=$ not available.

*Based on 2005 International Society of Urological Pathology Modified Gleason System.

${ }^{\dagger}$ Based on American Joint Committee on Cancer, 7th ed. 
$\mathrm{SUV}_{\text {max }}$ was invalid due to an error in uptake time data entry and this patient was excluded from the quantitative analysis.

\section{Primary treatment}

Patients were offered the best of care treatment depending on their co-morbidities, metastatic status and/or preference. When radical prostatectomy (RP) was selected, an extended bilateral pelvic LN dissection (PLND) was performed first. The PLND consisted in the removal of common iliac, internal iliac, external iliac and obturator LNs. Non-surgical patients were treated with androgen deprivation therapy (ADT) alone or in combination with radiation therapy (RT). Patients managed nonoperatively and with metastasis on staging FDG-PET/CT were re-imaged after at least 3 months of ADT to evaluate therapeutic response. Lesions with a radiological response/progression consistent with the biochemical evolution were considered true positive.

\section{Pathological assessment}

The following results were extracted from the clinical pathology reports: PCa involvement by sextant, percentage of prostatic tissue involved, pathological stage, pathological Gleason pattern and sum, LNs status and location.

\section{Statistical analyses}

Two validated post-operative prognostic tools that use clinico-pathological data to predict progression-free survival at 5 years were used: the CAPRA-S scores from University of California, San Francisco (UCSF) and the MSKCC nomogram from Memorial Sloan-Kettering Cancer Center [12-15]. Statistical tests were done using SAS v.9.3 software. Univariate analysis was performed using Pearson's chi-squared and Fisher's exact tests. Mann-Whitney $U$ test was used for two-group comparisons. Spearman correlations were performed for ordinal variables. All analyses were two-sided. A $P$-value $\leq 0.05$ indicated statistical significance.

\section{Results}

\section{Treatments and follow-up}

Forty-one patients underwent surgery (Figure 1). Of these, 39 had RP and PLND, while 2 had PLND only due to metastatic LN disease found at the time of surgery. Of the 41 operated patients, 11 (26.8\%) were found to harbour LN metastasis at pathology. The remaining 13 patients were treated with ADT, with or without RT. Baseline characteristics of the surgical and the nonsurgical groups are compared in Table 1. Pathological data for surgical patients are summarized in Table 2 . Among the 39 patients who underwent RP, the Gleason sum was downgraded from $\geq 8$ at biopsy to $\leq 7$ following

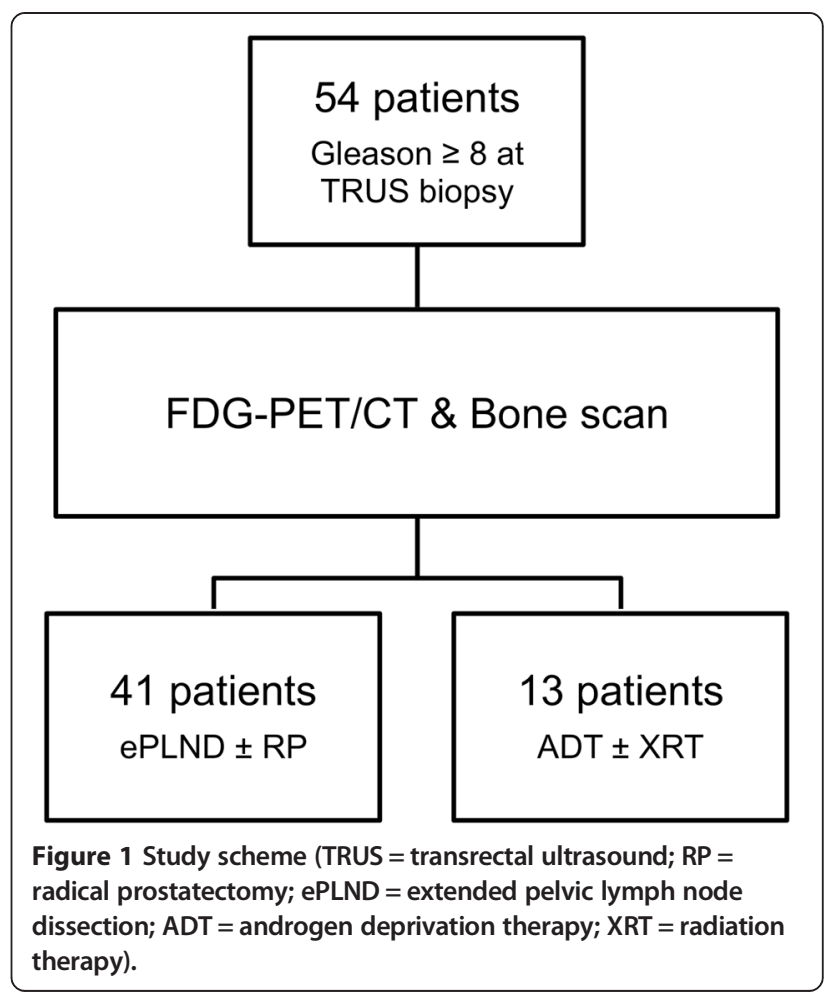

RP in 26 patients $(66.7 \%)$. All patients were followed-up for a median of 20 months (range: 15 to 24 months).

\section{FDG-PET/CT}

FDG-PET/CT results from clinical reports, blinded qualitative reading and quantitative analysis are presented on a per-patient basis in Table 3 and examples are depicted in Figure 2. The three patients with bone disease had their bone metastases detected by both FDG-PET/CT and bone scan (Figure 3). Of 7 patients with suspected LN metastasis on FDG-PET/CT, 3 had pathological confirmation at surgery and 4 had metabolic response after 3 months of ADT, consistent with a specificity of $100 \%$. FDG-PET/CT detected LN metastases in 3/11 (27\%) patients with pathology-proven LN disease at surgery.

\section{IPFU vs. clinico-pathological characteristics}

The associations between 10 clinico-pathological features and IPFU status are presented in Table 4. IPFU as described in clinical reports was statistically significantly associated with clinical stage, pathological Gleason sum, pathological Gleason pattern and the percentage of prostatic tissue involved by PCa (Table 4). Based on clinical reporting, negative IPFU conferred patients a 84.6\% probability of being downgraded to Gleason sum $\leq 7$ at $\mathrm{RP}$, which contrasts with a downgrading probability of $30.8 \%$ when IPFU was reported (Table 5). Moreover, all cases of Gleason sum 9 PCa post-RP did have IPFU, while none of the primary Gleason score 3 did. 
Table 2 Pathological characteristics of surgical patients $(n=41)^{*}$

\begin{tabular}{|c|c|c|}
\hline & & No. (\%) \\
\hline \multirow[t]{4}{*}{ Gleason score $^{\dagger}$} & 6 & $3(7.7)$ \\
\hline & 7 & $23(59.0)$ \\
\hline & 8 & $9(23.1)$ \\
\hline & 9 & $4(10.3)$ \\
\hline \multirow[t]{7}{*}{ Gleason pattern $^{\dagger}$} & $3+3$ & $2(5.1)$ \\
\hline & $3+4$ & $8(20.5)$ \\
\hline & $3+5$ & $1(2.6)$ \\
\hline & $4+3$ & $16(41.0)$ \\
\hline & $4+4$ & $8(20.5)$ \\
\hline & $4+5$ & $3(7.7)$ \\
\hline & $5+4$ & $1(2.6)$ \\
\hline \multirow[t]{8}{*}{ Pathological T stage ${ }^{\ddagger}$} & pT2a & $1(2.4)$ \\
\hline & pT2b & $3(7.3)$ \\
\hline & pT2c & $15(36.6)$ \\
\hline & рT3a & $9(22)$ \\
\hline & pT3b & $10(24.4)$ \\
\hline & pT4a & $1(2.4)$ \\
\hline & pT4b & $0(0.0)$ \\
\hline & pTx & $2(4.9)$ \\
\hline \multirow[t]{2}{*}{ Margins } & Negative & $23(59.0)$ \\
\hline & Positive & $16(41.0)$ \\
\hline \multirow[t]{2}{*}{ Extracapsular extension } & No & $21(53.8)$ \\
\hline & Yes & $18(46.2)$ \\
\hline \multirow[t]{2}{*}{ SV invasion } & No & $28(71.8)$ \\
\hline & Yes & $11(28.2)$ \\
\hline \multirow[t]{3}{*}{ Perineural invasion } & No & $5(12.8)$ \\
\hline & Yes & $19(48.7)$ \\
\hline & n/a & $15(38.5)$ \\
\hline Intraprostatic cancer extent (Mean \% (SD)) & - & $27.3(22.9)$ \\
\hline \multirow[t]{2}{*}{ Pathological N stage f $^{\ddagger}$} & pNO & $30(73.2)$ \\
\hline & $\mathrm{pN1}$ & $11(26.8)$ \\
\hline Number of LN (Mean (SD)) & - & $17.6(7.3)$ \\
\hline LN density (Mean (SD)) & - & $3.6(8.3)$ \\
\hline
\end{tabular}

$\mathrm{LN}=$ lymph nodes; SD = standard deviation; SV = seminal vesicles; $\mathrm{n} / \mathrm{a}=$ not available.

*39 patients underwent radical prostatectomy with extended pelvic lymph node dissection and 2 patients underwent extended pelvic lymph node dissection only.

${ }^{\dagger}$ Based on 2005 International Society of Urological Pathology Modified Gleason System.

${ }^{\ddagger}$ Based on American Joint Committee on Cancer, 7th ed.

Similarly, quantitative IPFU based on $\mathrm{SUV}_{\max }$ was statistically significantly associated with pathological Gleason sum and percentage of intraprostatic cancer (Table 4). $\mathrm{SUV}_{\text {max }}$ was significantly higher in patients with Gleason sum $\geq 8$ than those with Gleason sum $\leq 7$ at final pathology
Table 3 FDG-PET/CT results

\begin{tabular}{|c|c|c|c|}
\hline & $\begin{array}{l}\text { All patients } \\
(n=54)\end{array}$ & $\begin{array}{l}\text { Surgical patients } \\
(n=41)\end{array}$ & $\begin{array}{l}\text { Non-surgical } \\
\text { patients }(n=13)\end{array}$ \\
\hline & No. (\%) & No. (\%) & No. (\%) \\
\hline \multicolumn{4}{|l|}{ Clinical report } \\
\hline IPFU+ & $24(44.4)$ & $15(36.6)$ & $9(69.2)$ \\
\hline $\begin{array}{l}\text { Lymph node } \\
\text { metastasis }\end{array}$ & $7(13.0)$ & $3(7.3)$ & $4(30.8)$ \\
\hline Bone metastasis & $3(6.0)$ & $0(0.0)$ & $3(23.1)$ \\
\hline \multicolumn{4}{|l|}{ Blinded reading* } \\
\hline IPFU score 0 & $6(11.1)$ & $6(14.6)$ & $0(0.0)$ \\
\hline IPFU score 1 & 18 (33.3) & 15 (36.6) & $3(23.1)$ \\
\hline IPFU score 2 & $14(25.9)$ & $12(29.3)$ & $2(15.3)$ \\
\hline IPFU score 3 & $10(18.5)$ & $6(14.6)$ & $4(30.8)$ \\
\hline IPFU score 4 & $6(11.1)$ & $2(4.9)$ & $4(30.8)$ \\
\hline $\begin{array}{l}\text { IPFU+ (score } 2 \\
\text { to 4) }\end{array}$ & $30(55.6)$ & $20(48.9)$ & $13(76.9)$ \\
\hline \multicolumn{4}{|c|}{ Quantitative analysis } \\
\hline \multirow{2}{*}{$\begin{array}{l}\text { IPFU+ } \\
\left(\mathrm{SUV}_{\max } \geq 4.0\right)\end{array}$} & $24(44.4)$ & $15(36.6)$ & $9(69.2)$ \\
\hline & Median (range) & Median (range) & Median (range) \\
\hline Prostatic SUV $\max$ & $3.7(1.8-34.7)$ & $3.5(1.8-24.9)$ & $5.9(2.5-34.7)$ \\
\hline
\end{tabular}

(6.62 \pm 6.25 vs. $3.53 \pm 1.32$, respectively; $P=0.020)$, and $\mathrm{SUV}_{\text {max }} \geq 4$ was significantly associated with pathological Gleason sum $\geq 8$ (Table 5). Conversely, in 39 patients who underwent RP, low IPFU ( $\left.\mathrm{SUV}_{\max }<4.0\right)$ conferred patients an $83.3 \%$ probability of the Gleason sum being downgraded from $\geq 8$ at biopsy to $\leq 7$ at pathology. This probability was $85.0 \%$ when using qualitative IPFU assessment from the blinded reading (Table 5).

Statistically significant positive correlations were found between $\mathrm{SUV}_{\max }$ and visual uptake score on one hand, and post-RP Gleason pattern, Gleason sum and pathological T stage on the other hand (Table 5 and Figure 4).

\section{IPFU vs. post-radical prostatectomy prognosis}

IPFU was compared with the predicted 5-year progression-free survival, as determined by the CAPRA-S and MSKCC nomograms (Table 6) [12-15]. There was a statistically significant difference in predicted 5-year progression-free survival between patients with or without significant IPFU.

\section{Discussion}

Treatment decision after PCa diagnosis is complicated by the variability of disease progression and the diversity of treatments available. To predict $\mathrm{PCa}$ behaviour, a number of clinical tools have been developed. One of 
A

D
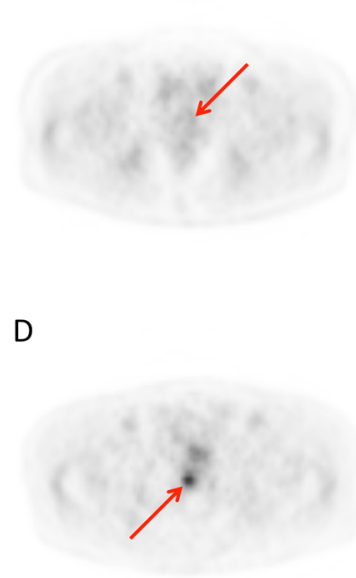

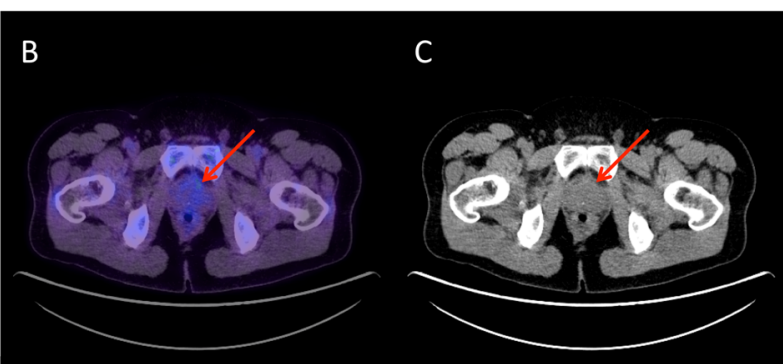

E F
(1)

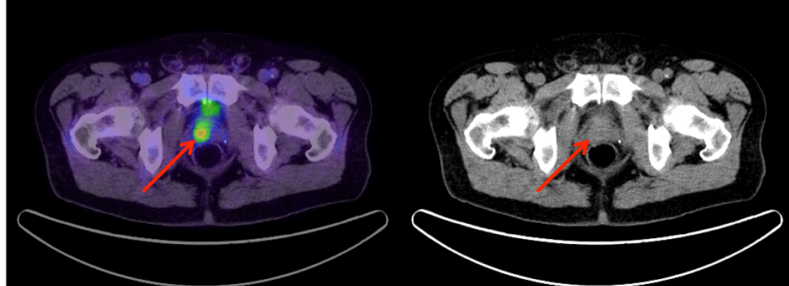

Figure 2 Examples of corresponding transaxial PET (A, D), fused PET/CT (B, E) and CT (C, F) slices. A patient (A-C) had a Gleason sum 8 (4+4) $\mathrm{PCa}$ at biopsy and the most prominent focus of prostatic FDG uptake was only faintly noticeable (negative clinical report; $\mathrm{Score}=1$; $\mathrm{SUV}$ max $=2.7$ ). His PCa was downgraded to Gleason sum $6(3+3)$ after RP. Conversely, another patient (D-F) also had a Gleason sum 8 (4+4) PCa at biopsy, but FDG-PET/CT showed a highly hypermetabolic prostatic focus (positive clinical report; Score $=3$; SUV $\max =8.2$ ). His PCa was upgraded to Gleason sum 9 $(5+4)$ following RP.

the simplest is the D'Amico's risk definition [1]. Most guidelines are based on this classification for treatment recommendations $[16,17]$. However, the high-risk category includes a wide range of tumour volumes and PSA levels, and also biologically heterogeneous tumours, some being high-grade, highly aggressive tumours (Gleason 9-10), while other being downgraded to Gleason $\leq 7$ at post-RP pathology. Indeed, for high-risk PCa, there is a need for better pre-treatment disease characterization to optimize treatment strategy. Staging is of prime importance in this setting because loco-regional treatment with RP and/or $\mathrm{RT}$ is rarely curative when there is LN metastasis. But radiological size-based $\mathrm{LN}$ metastasis detection has a poor accuracy [18].

In the last two decades, a number of PET radiopharmaceuticals have been developed for PCa. Of these, ${ }^{11} \mathrm{C}$ choline and ${ }^{18} \mathrm{~F}$-fluorocholine $(\mathrm{FCH})$ have been the most studied clinically [19]. Choline radiopharmaceuticals are reputed having a higher uptake in PCa cells than FDG [19], although this is not well established specifically for high-grade $\mathrm{PCa}$. Recent studies in large cohorts have shown promising results for FCH-PET/CT as a staging tool. For example, Beheshti et al. have shown that FCHPET sensitivity and specificity for PCa LN metastasis detection were $66 \%$ and $96 \%$, respectively [20]. Therefore, by comparing these results to ours (27\% LN detection sensitivity in surgical patients, $47 \%$ overall), it seems that FCH may be superior to FDG for PCa LN staging. More recently, Haseebuddin et al. studied the role of ${ }^{11} \mathrm{C}$-acetate-PET/CT in the primary staging of intermediate and high-risk PCa with negative conventional imaging [21].
They reported a significant difference in 3-year treatment failure probability of 82 and $51 \%$, respectively, when metastasis was found or not, respectively, on preoperative ${ }^{11} \mathrm{C}$-acetate imaging. One could suggest that $\mathrm{LN}$ positivity on $\mathrm{FCH}$ - or ${ }^{11} \mathrm{C}$-acetate-PET would carry a greater prognostic value than IPFU, but this is questionable. In fact, reported recurrence-free status at 5 years in patients harbouring $\mathrm{pN} 1$ disease (without adjuvant ADT) is approximately 20 to $26 \%$ [22,23]. This is similar to the percentage of patients predicted to be disease-free at 5 years by CAPRA-S nomogram when IPFU is present, which was $26.9 \%$ in our series. Moreover, $27 \%$ (3/11) of pathologically-proven LN metastasis were identified by FDG-PET/CT and the two patients for whom CAPRA-S calculation was possible (one did not undergo RP) had a predicted 5-year recurrence-free survival of $0 \%$. This shows the potentially enhanced discriminative prognostic capability of the widely available FDG radiopharmaceutical compared with choline or acetate tracers.

Moreover, in our series, FCH-PET would theoretically have identified only 7 patients with LN metastasis $(66 \%$ of 11 pN1) while FDG-PET identified 15 patients with a high local treatment failure probability based on IPFU. Indeed, the tumour biology (or intrinsic aggressiveness) might be as important to consider pre-operatively as LN staging, since some aggressive cancers will metastasize systemically, skipping LN transition. This is consistent with the observation that 2 out of our 3 patients with bone metastasis had IPFU and FDG-positive bone metastasis without any evidence of LN metastasis. In their series of metastatic castration-resistant PCa (CRPC) 


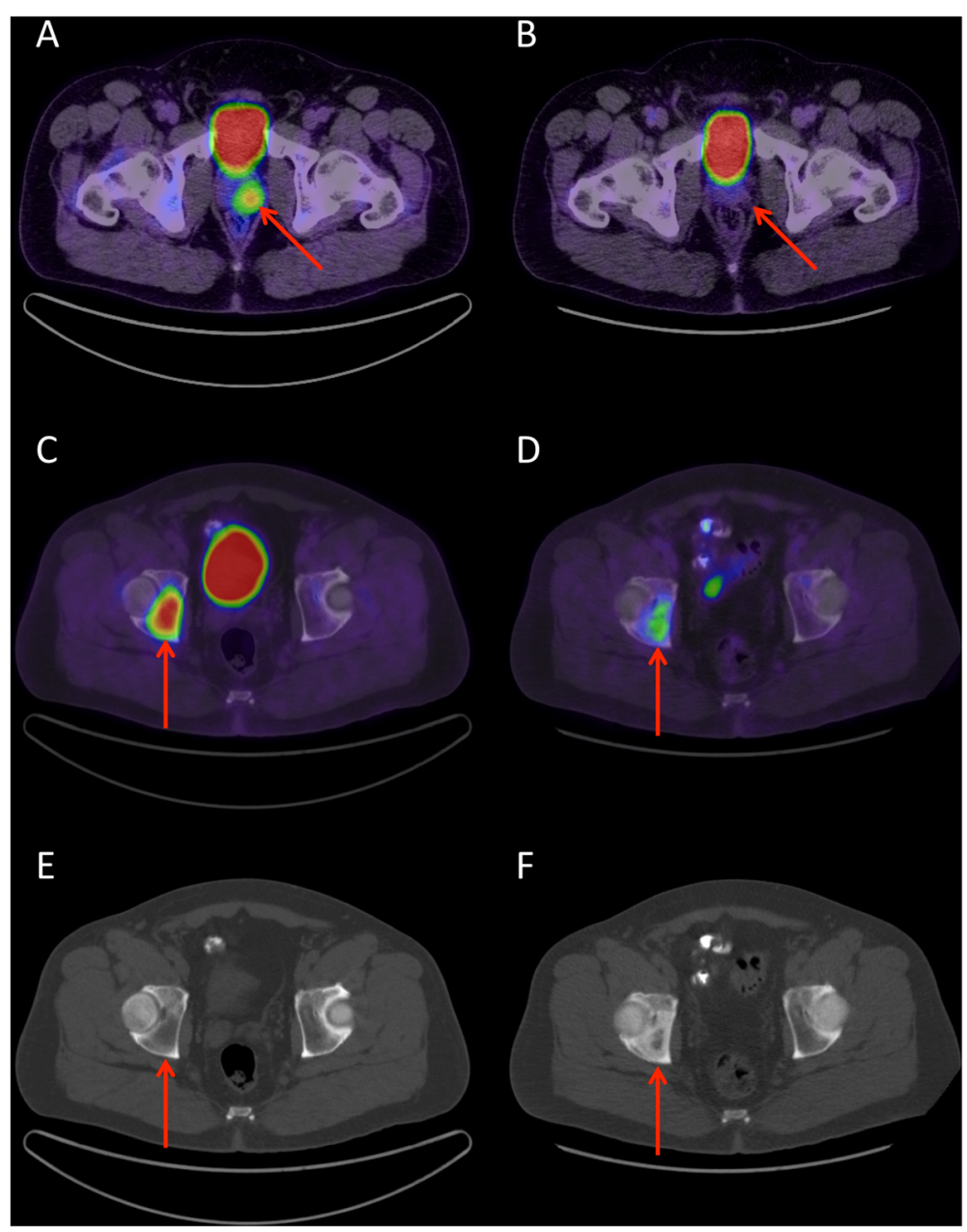

Figure 3 Fused FDG-PET/CT transaxial slices in a patient with a Gleason sum $9(4+5)$ PCa at biopsy showing (A) a highly hypermetabolic prostatic focus (positive clinical report; score $=3 ; S V_{\max }=7.1$ ) and $(C)$ one of two bone metastases, which were intensely hypermetabolic and lytic on CT (E). Three months after ADT initiation, there was a complete metabolic response of the primary PCa lesion (B). The bone lesions

underwent at least a partial metabolic response (D) and became sclerotic on $C T$ (F). Possibly, the osteoblasts repair activity contributed to the residual FDG uptake. The metabolic response was consistent with the biochemical response, with the PSA decreasing from 125 to $1.5 \mathrm{ng} / \mathrm{L}$.

imaged by FDG-PET, Jadvar et al. observed that $41.4 \%$ of their patients had bone-only metastases while $5.7 \%$ had both bone and soft tissue metastases [5]. This suggests that radiological and/or surgical LN staging is insufficient for prognostic stratification of high-grade $\mathrm{PCa}$ patients. Taken together, these results suggest that FDG$\mathrm{PET} / \mathrm{CT}$, as a single imaging modality, can identify many patients at high risk of local treatment failure, possibly with better discriminative prognostic capability than choline- or acetate-PET. Prospective trials directly comparing FDG with these tracers in patients with highgrade $\mathrm{PCa}$ at biopsy are warranted to ascertain this hypothesis.

The prognostic capability of FDG-PET/CT in highgrade $\mathrm{PCa}$ is not counterintuitive. The prognostic value of FDG-PET/CT was shown in patients with metastatic PCa by Meirelles et al., who reported that FDG uptake in metastatic lesions of 51 patients (39 CRPC and 12 castration-sensitive) was correlated to prognosis [4]. Jadvar et al. reported that the summed FDG uptake $\left(\mathrm{SUV}_{\max }\right)$ of metastatic lesions could predict overall survival in a large cohort of 87 CRPC patients [5]. In our series, higher metabolic activity of the primary PCa correlated strongly with higher pathological Gleason sum and predicted nomogram-derived prognosis. Together, these results suggest that PCa with higher glucose metabolism is associated with a poorer prognosis, both at early and late stages of the disease evolution. Whether increased FDG uptake is maintained throughout the course of the disease or acquired after clonal selection under ADT remains to be elucidated, but early identification of IPFU might prompt a more aggressive systemic management, even in apparently localized PCa. 
Table 4 Clinico-pathological features associated with intraprostatic FDG uptake

\begin{tabular}{|c|c|c|c|c|c|c|c|}
\hline & & \multicolumn{3}{|c|}{ Clinical reporting } & \multicolumn{3}{|c|}{ Quantitative analysis } \\
\hline & & IPFU- & IPFU+ & $P$-value & $\mathrm{SUV}_{\max }<4.0$ & $S U_{\max } \geq 4.0$ & $P$-value \\
\hline & & No. (\%) & No. (\%) & & No. (\%) & No. (\%) & \\
\hline \multirow[t]{4}{*}{ Clinical T stage* } & cT1 & $12(48.0)$ & $6(26.1)$ & 0.042 & $12(50.0)$ & $6(27.3)$ & 0.13 \\
\hline & cT2 & $10(40.0)$ & $6(26.1)$ & & $9(37.5)$ & $7(31.8)$ & \\
\hline & cT3 & $3(12.0)$ & $8(34.8)$ & & $3(12.5)$ & $7(31.8)$ & \\
\hline & cT4 & $0(0.0)$ & $3(13.0)$ & & $0(0.0)$ & $2(9.1)$ & \\
\hline \multirow[t]{3}{*}{ Pretreatment PSA $(\mathrm{ng} / \mathrm{ml})$} & $<10.0$ & $23(76.7)$ & $13(54.2)$ & 0.21 & $23(79.3)$ & $12(52.2)$ & 0.12 \\
\hline & 10.0-19.9 & $5(16.7)$ & $7(29.2)$ & & $4(13.8)$ & $7(30.4)$ & \\
\hline & $\geq 20.0$ & $2(6.7)$ & $4(16.7)$ & & $2(6.9)$ & $4(17.4)$ & \\
\hline \multirow[t]{3}{*}{ Pathological T stage* } & pT2 & $14(53.8)$ & $5(38.5)$ & 0.28 & $14(58.3)$ & $5(35.7)$ & 0.17 \\
\hline & pT3 & $12(46.2)$ & $7(53.8)$ & & $10(41.7)$ & $8(57.1)$ & \\
\hline & pT4 & $0(0.0)$ & $1(7.7)$ & & $0(0.0)$ & $1(7.1)$ & \\
\hline \multirow[t]{2}{*}{ Pathological N stage* } & $\mathrm{pNO}$ & $21(80.8)$ & $9(60.0)$ & 0.15 & $21(84.0)$ & $9(60.0)$ & 0.090 \\
\hline & $\mathrm{pN} 1$ & $5(19.2)$ & $6(40.0)$ & & $4(16.0)$ & $6(40.0)$ & \\
\hline \multirow[t]{4}{*}{ Gleason score $^{\dagger}$} & 6 & $3(11.5)$ & $0(0.0)$ & 0.002 & $3(12.5)$ & $0(0.0)$ & 0.029 \\
\hline & 7 & $19(73.1)$ & $4(30.8)$ & & $17(70.8)$ & $6(42.9)$ & \\
\hline & 8 & $4(15.4)$ & $5(38.5)$ & & $4(16.7)$ & $5(35.7)$ & \\
\hline & 9 & $0(0.0)$ & $4(30.8)$ & & $0(0.0)$ & $3(21.4)$ & \\
\hline \multirow[t]{7}{*}{ Gleason pattern $^{\dagger}$} & $3+3$ & $2(7.7)$ & $0(0.0)$ & 0.009 & $2(8.3)$ & $0(0.0)$ & 0.062 \\
\hline & $3+4$ & $8(30.8)$ & $0(0.0)$ & & $7(29.2)$ & $1(7.1)$ & \\
\hline & $3+5$ & $1(3.8)$ & $0(0.0)$ & & $1(4.2)$ & $0(0.0)$ & \\
\hline & $4+3$ & $12(46.2)$ & $4(30.8)$ & & $11(45.8)$ & $5(35.7)$ & \\
\hline & $4+4$ & $3(11.5)$ & $5(38.5)$ & & $3(12.5)$ & $5(35.7)$ & \\
\hline & $4+5$ & $0(0.0)$ & $3(23.1)$ & & $0(0.0)$ & $2(14.3)$ & \\
\hline & $5+4$ & $0(0.0)$ & $1(7.7)$ & & $0(0.0)$ & $1(7.1)$ & \\
\hline \multirow[t]{3}{*}{ Intraprostatic cancer extent } & $0-9 \%$ & $8(30.8)$ & $0(0.0)$ & 0.027 & $8(33.3)$ & $0(0.0)$ & 0.046 \\
\hline & $10-49 \%$ & $15(57.7)$ & $7(58.3)$ & & $13(54.2)$ & $9(69.2)$ & \\
\hline & $\geq 50 \%$ & $3(11.5)$ & $5(41.7)$ & & $3(12.5)$ & $4(30.8)$ & \\
\hline \multirow[t]{2}{*}{ Margins } & Negative & $15(57.7)$ & $8(61.5)$ & 0.82 & $15(62.5)$ & $8(57.1)$ & 0.74 \\
\hline & Positive & $11(42.3)$ & $5(38.5)$ & & $9(37.5)$ & $6(42.9)$ & \\
\hline \multirow[t]{2}{*}{ Extracapsular extension } & No & $15(57.7)$ & $6(46.2)$ & 0.50 & $15(62.5)$ & $6(42.9)$ & 0.24 \\
\hline & Yes & $11(42.3)$ & $7(53.8)$ & & $9(37.5)$ & $8(57.1)$ & \\
\hline \multirow[t]{2}{*}{ SV invasion } & No & $20(76.9)$ & $8(61.5)$ & 0.31 & $19(79.2)$ & $8(57.1)$ & 0.15 \\
\hline & Yes & $6(23.1)$ & $5(38.5)$ & & $5(20.8)$ & $6(42.9)$ & \\
\hline
\end{tabular}

FDG $={ }^{18}$ F-fluorodeoxyglucose; IPFU = intraprostatic FDG uptake; IPFU- = IPFU-negative; IPFU+ = IPFU-positive; PSA = prostate-specific antigen; SV = seminal vesicles. *Based on American Joint Committee on Cancer, 7th ed.

${ }^{\dagger}$ Based on 2005 International Society of Urological Pathology Modified Gleason System.

A unique feature of FDG-PET when compared to choline-PET is its ability to predict post-RP Gleason sum and pattern. Most choline-PET studies did not find any correlation between intraprostatic choline uptake and Gleason sum [24-26]. In our study, negative IPFU indicated an $84.6 \%$ probability that a patient would be downgraded to Gleason $\leq 7$ at RP. Moreover, there was a significant correlation between IPFU $\left(\mathrm{SUV}_{\max }\right.$ and score) and post-RP Gleason pattern and sum. A potential role for FDG-PET/CT could be the assessment of IPFU to guide adjuvant ADT duration decisions when RT is the primary treatment. The optimal length of ADT in D'Amico's high-risk patients is still debated, and it may be that IPFU-negative patients could be suitable for shorter ADT duration. FDGPET/CT could also prospectively identify patients for whom peri-operative chemotherapy or new ADT drugs could be beneficial. 
Table 5 Intraprostatic FDG uptake as a predictor of pathological Gleason sum

\begin{tabular}{|c|c|c|c|c|}
\hline & \multicolumn{2}{|c|}{ Pathological Gleason sum } & \multirow[t]{3}{*}{ Spearman $r$} & \multirow[t]{3}{*}{$P$-value } \\
\hline & $\leq 7$ & $\geq 8$ & & \\
\hline & No. $(\%)$ & No. (\%) & & \\
\hline \multicolumn{5}{|l|}{ Clinical reporting } \\
\hline IPFU- & $22(84.6)$ & $4(15.4)$ & & 0.003 \\
\hline IPFU+ & $4(30.8)$ & $9(69.2)$ & & \\
\hline \multicolumn{5}{|l|}{ Blinded reading } \\
\hline IPFU- (Score 0 or 1$)$ & $17(85.0)$ & $3(15.0)$ & & 0.013 \\
\hline IPFU+ (Score 2 to 4) & $9(47.4)$ & $10(52.6)$ & & \\
\hline Score vs. post-RP Gleason pattern & & & 0.58 & 0.0001 \\
\hline Score vs. post-RP Gleason sum & & & 0.50 & 0.001 \\
\hline Score vs. pathological T stage & & & 0.32 & 0.040 \\
\hline \multicolumn{5}{|l|}{ Quantitative analysis } \\
\hline IPFU- $\left(S U V_{\max }<4.0\right)$ & $20(83.3)$ & $4(16.7)$ & & 0.010 \\
\hline IPFU+ (SUV $\max \geq 4.0)$ & $6(42.9)$ & $8(57.1)$ & & \\
\hline$S U V_{\max }$ VS. post-RP Gleason pattern & & & 0.46 & 0.004 \\
\hline SUV $V_{\max }$ Vs. post-RP Gleason sum & & & 0.44 & 0.006 \\
\hline $\mathrm{SUV}_{\max }$ VS. pathological T stage & & & 0.35 & 0.030 \\
\hline
\end{tabular}

FDG $={ }^{18} \mathrm{~F}$-fluorodeoxyglucose; IPFU = intraprostatic FDG uptake; IPFU- = IPFU-negative; IPFU + = IPFU-positive; RP = radical prostatectomy; SUV $_{\text {max }}=$ maximum standardized uptake value.

Our study has some limitations. Firstly, the clinical reporting of FDG-PET/CT may have been biased by the variability among attending nuclear medicine physicians in their interpretation of what constitutes significant or suspicious IPFU. However, the systematic blinded reading with qualitative IPFU assessment and the quantitative analysis both corroborate the results derived from clinical reporting. Secondly, most conclusions are based on the surgical subgroup. Because treatment decision was left to the surgeon and the patient (standard of care), many cases of FDG-positive LN or bone metastasis and/or unresectable disease could not be verified pathologically. Since all of them had a metabolic

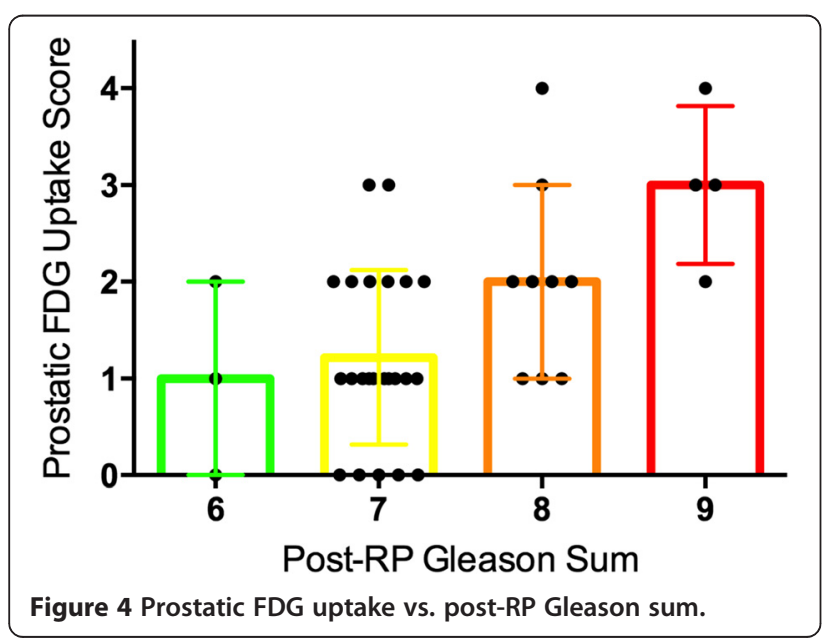

Table 6 Intraprostatic FDG uptake as a predictor of the predicted 5-year progression-free survival by CAPRA-S and MSKCC nonograms

\begin{tabular}{lllll}
\hline CAPRA-S* $^{*}$ & & & MSKCC $^{\dagger}$ & \\
\cline { 2 - 3 } \cline { 5 - 6 } $\begin{array}{llll}\text { Median \% } \\
\text { (25th }-75 \text { th } \\
\text { percentile) }\end{array}$ & P-value & & $\begin{array}{l}\text { Median \% } \\
(25 \text { th }-75 \text { th }\end{array}$ & P-value \\
& & & percentile) \\
\hline
\end{tabular}

\section{Clinical reporting}

$\begin{array}{lllll}\text { IPFU- } & 70.2(26.7-85.2) & 0.008 & 91.5(77.0-97.0) & 0.004 \\ \text { IPFU+ } & 25.9(0.0-42.5) & & 59.0(42.0-88.0) & \end{array}$

\section{Blinded reading}

\begin{tabular}{|c|c|c|c|c|}
\hline $\begin{array}{l}\text { IPFU- } \\
\text { (Score } 0 \text { or 1) }\end{array}$ & $70.2(34.2-91.0)$ & 0.017 & $93.0(81.0-97.5)$ & 0.010 \\
\hline $\begin{array}{l}\text { IPFU+ } \\
\text { (Score } 2 \text { to } 4 \text { ) }\end{array}$ & $26.9(0.0-63.3)$ & & $73.0(45.3-89.8)$ & \\
\hline \multicolumn{5}{|c|}{ Quantitative analysis } \\
\hline $\begin{array}{l}\text { IPFU- } \\
(\text { SUV } \\
\text { max }<4.0)\end{array}$ & $70.2(26.7-85.2)$ & 0.030 & $91.5(72.8-97.0)$ & 0.020 \\
\hline$U_{+}$ & $25.9(0.0-42.5)$ & & $72.0(45.0-89.0)$ & \\
\hline
\end{tabular}

$\left(S U V_{\text {max }} \geq 4.0\right)$

FDG $={ }^{18}$ F-fluorodeoxyglucose; IPFU = intraprostatic FDG uptake; IPFU- = IPFUnegative; IPFU + = IPFU-positive; $\mathrm{SUV}_{\max }=$ maximum standardized uptake value.

*University of California, San Franciso Cancer of the Prostate Risk Assessment score: Post-Radical Prostatectomy nomogram.

${ }^{\dagger}$ Memorial Sloan-Kettering Cancer Center post-radical prostatectomy nomogram. 
response to $\mathrm{ADT}$ after reimaging at 3 months, their metastatic status was probably true positive. Likely, the LN sensitivity of $27 \%$ in our surgical group is an underestimation of the overall sensitivity of FDG for detection of $\mathrm{LN}$ metastasis, which may be closer to $47 \%$ (7/15, when including the 4 non-surgical patients with FDGpositive LN). Finally, IPFU's prognostic ability was shown indirectly using two prognostic nomograms, the CAPRA-S and the MSKCC. Certainly, the gold standard to demonstrate the prognostic value of FDG-PET/CT will be our cohort's actual progression-free survival, which will be assessed in the upcoming years. However, we are confident that the estimated prognostic ability of FDG-PET/CT is real since it is based on two of the most validated prognostic tools [12-15]. Moreover, we have shown that IPFU was associated with higher pathological Gleason sum and pattern, and percentage of intraprostatic cancer, all of which have been described as being of prognostic value $[15,27,28]$. Hence, it is highly expected that actual progression-free survival will be different between low/negative and high/ positive IPFU, as the latter might represent the integration of these poor-prognosis pathological features that are only known after surgery.

\section{Conclusions}

Our results suggest that molecular imaging of patients with high-grade PCa at biopsy using FDG-PET/CT could be useful for both staging and prognostic stratification. Intraprostatic FDG uptake assessment with PET/CT may represent the integration of a number of important pathological features, making this crucial prognostic information available before primary therapy. Hence, FDG-PET/CT has the potential to enable improved and personalized care management in this selected $\mathrm{PCa}$ patient population, which is most at risk of therapy failure and shortened survival.

\section{Competing interests}

The authors declare that they have no competing interests.

\section{Authors' contributions}

All authors read and approved the final manuscript. Study concept and design: JMB, ACB, FP. Acquisition of data: JMB, ACB, VF, YF, CL, LL, TD, RT, GR, FP. Analysis and interpretation of data: $J \mathrm{MB}, \mathrm{ACB}, \mathrm{AC}$, FP. Drafting of the manuscript: JMB, ACB, FP. Critical revision of the manuscript for important intellectual content: JMB, FP. Statistical analysis: AC, FB. Obtaining funding: $J M B, A C B, F P$. Administrative, technical, or material support: None. Supervision: $J M B$, FP. Other (specify): None.

\section{Acknowledgements}

We thank Prostate Cancer Canada and Movember for Clinician Scientist and Rising star awards to F.P., the Canadian Urological Oncology Group for a grant to F.P. and A.-C.B., the Canadian Urological Association Scholarship (F. P.) and the Fonds de la Recherche du Québec en Santé (F.R.Q.S.) for Clinician Scientist Scholarships to F.P. J.M.B. and V.F.. We also thank Drs Francis Morin and Juan Friede, nucleists, for FDG-TEP-CT readings.

\section{Author details}

'Division of Nuclear Medicine, Department of Radiology and Cancer Research Center, Université Laval, Quebec City, Canada. ${ }^{2}$ Division of Nuclear
Medicine, Department of Medical Imaging and Oncology Axis of $\mathrm{CHU}$ de Québec Research Center, CHU de Québec, Quebec City, Canada. ${ }^{3}$ Division of Urology, Department of Surgery and Cancer Research Center, Université Laval, Quebec City, Canada. ${ }^{4}$ Division of Urology, Department of Surgery and Oncology Axis of CHU de Québec Research Center, CHU de Québec, Quebec City, Canada. ${ }^{5}$ Centre hospitalier du Christ-Roi, Quebec City, Canada.

Received: 30 July 2014 Accepted: 20 February 2015

Published online: 03 March 2015

\section{References}

1. D'Amico AV, Moul J, Carroll PR, Sun L, Lubeck D, Chen MH. Cancer-specific mortality after surgery or radiation for patients with clinically localized prostate cancer managed during the prostate-specific antigen era. J Clin Oncol. 2003;21:2163-72.

2. Pouliot F, Johnson M, Wu L. Non-invasive molecular imaging of prostate cancer lymph node metastasis. Trends Mol Med. 2009;15:254-62.

3. Jadvar H. Prostate cancer: PET with ${ }^{18} \mathrm{~F}-\mathrm{FDG},{ }^{18} \mathrm{~F}$ - or ${ }^{11} \mathrm{C}$-acetate, and ${ }^{18} \mathrm{~F}$ - or ${ }^{11}$ C-choline. J Nucl Med. 2011;52:81-9.

4. Meirelles GS, Schöder H, Ravizzini GC, Gonen M, Fox JJ, Humm J, et al. Prognostic value of baseline $\left[{ }^{18} \mathrm{~F}\right]$ fluorodeoxyglucose positron emission tomography and ${ }^{99 \mathrm{~m}} \mathrm{Tc}-\mathrm{MDP}$ bone scan in progressing metastatic prostate cancer. Clin Cancer Res. 2010;16:6093-9.

5. Jadvar H, Desai B, Conti PS, Conti PS, Dorff TB, Groshen SG, et al. Baseline ${ }^{18}$ F-FDG PET/CT parameters as imaging biomarkers of overall survival in castrate-resistant metastatic prostate cancer. J Nucl Med. 2013;54:1195-201.

6. Salminen E, Hogg A, Binns D, Frydenberg M, Hicks RJ. Investigations with FDG-PET scanning in prostate cancer show limited value for clinical practice. Acta Oncol. 2002;41:425-9.

7. Jana S, Blaufox MD. Nuclear medicine studies of the prostate, testes, and bladder. Semin Nucl Med. 2006;36:51-72.

8. Chang CH, Wu HC, Tsai JJ, Shen YY, Changlai SP, Kao A. Detecting metastatic pelvic lymph nodes by ${ }^{18} \mathrm{~F}$-2-deoxyglucose positron emission tomography in patients with prostate-specific antigen relapse after treatment for localized prostate cancer. Urol Int. 2003;70:311-5.

9. Beauregard JM, Williams SG, Degrado TR, Roselt P, Hicks RJ. Pilot comparison of ${ }^{18} \mathrm{~F}$-fluorocholine and ${ }^{18} \mathrm{~F}$-fluorodeoxyglucose PET/CT with conventional imaging in prostate cancer. J Med Imaging Radiat Oncol. 2010;54:325-32.

10. Stewart GD, Gray K, Pennington CJ, Edwards DR, Riddick ACP, Ross JA, et al. Analysis of hypoxia-associated gene expression in prostate cancer: lysyl oxidase and glucose transporter-1 expression correlate with Gleason score. Oncol Rep. 2008:20:1561-7.

11. Effert P, Beniers AJ, Tamimi Y, Handt S, Jakse G. Expression of glucose transporter 1 (Glut-1) in cell lines and clinical specimens from human prostate adenocarcinoma. Anticancer Res. 2004;24:3057-63.

12. Punnen S, Freedland SJ, Presti Jr JC, Aronson WJ, Terris MK, Kane CJ, et al. Multi-institutional validation of the CAPRA-S score to predict disease recurrence and mortality after radical prostatectomy. Eur Urol. 2013;65:1171-7.

13. Cooperberg MR, Hilton JF, Carroll PR. The CAPRA-S score: a straightforward tool for improved prediction of outcomes after radical prostatectomy. Cancer. 2011;117:5039-46.

14. Kattan MW, Wheeler TM, Scardino PT. Postoperative nomogram for disease recurrence after radical prostatectomy for prostate cancer. J Clin Oncol. 1999;17:1499-507.

15. Stephenson AJ, Scardino PT, Eastham JA, Bianco FJ, Dotan ZA, DiBlasio CJ, et al. Postoperative nomogram predicting the 10-year probability of prostate cancer recurrence after radical prostatectomy. J Clin Oncol. 2005;23:7005-12.

16. Carter HB, Albertsen PC, Barry MJ, Etzioni R, Freedland SJ, Greene KL, et al. Early detection of prostate cancer: AUA guideline. J Urol. 2013;190:419-26.

17. Heidenreich A, Bellmunt J, Bolla M, Joniau S, Mason M, Matveev V, et al. EAU guidelines on prostate cancer. Part 1: screening, diagnosis, and treatment of clinically localised disease. Eur Urol. 2011;59:61-71.

18. Hövels AM, Heesakkers RA, Adang EM, Jager GJ, Strum S, Hoogeveen YL, et al. The diagnostic accuracy of $C T$ and MRI in the staging of pelvic lymph nodes in patients with prostate cancer: a meta-analysis. Clin Radiol. 2008;63:387-95. 
19. Bauman G, Belhocine T, Kovacs M, Ward A, Beheshti M, Rachinsky I. ${ }^{18}$ Ffluorocholine for prostate cancer imaging: a systematic review of the literature. Prostate Cancer Prostatic Dis. 2012;15:45-55.

20. Beheshti M, Imamovic L, Broinger G, Vali R, Waldenberger $P$, Stoiber $F$, et al. ${ }^{18} \mathrm{~F}$ choline PET/CT in the preoperative staging of prostate cancer in patients with intermediate or high risk of extracapsular disease: a prospective study of 130 patients. Radiology. 2010;254:925-33.

21. Haseebuddin M, Dehdashti F, Siegel BA, Liu J, Roth EB, Nepple KG, et al. ${ }^{11} \mathrm{C}$-acetate PET/CT before radical prostatectomy: nodal staging and treatment failure prediction. J Nucl Med. 2013;54:699-706.

22. Briganti A, Karmes JR, Da Pozzo LF, Cozzarini C, Gallina A, Suardi N, et al. Two positive nodes represent a significant cut-off value for cancer specific survival in patients with node positive prostate cancer. A new proposal based on a two-institution experience on 703 consecutive $\mathrm{N}+$ patients treated with radical prostatectomy, extended pelvic lymph node dissection and adjuvant therapy. Eur Urol. 2009;55:261-70.

23. Briganti A, Blute ML, Eastham JH, Graefen M, Heidenreich A, Karnes JR, et al. Pelvic lymph node dissection in prostate cancer. Eur Urol. 2009;55:1251-65.

24. Kitajima K, Murphy RC, Nathan MA. PET/CT for imaging prostate cancer: an update. Ann Nucl Med. 2013;27:581-91.

25. Farsad M, Schiavina R, Castellucci P, Nanni C, Corti B, Martorana G, et al. Detection and localization of prostate cancer: correlation of ${ }^{11} \mathrm{C}$-choline PET/CT with histopathologic step-section analysis. J Nucl Med. 2005:46:1642-9.

26. Giovacchini G, Picchio M, Coradeschi E, Cattoni V, Bettinardi V, Cozzarini C, et al. $\left[{ }^{11} \mathrm{C}\right]$ choline uptake with PET/CT for the initial diagnosis of prostate cancer: relation to PSA levels, tumour stage and anti-androgenic therapy. Eur J Nucl Med Mol Imaging. 2008:35:1065-73.

27. Kotb AF, Tanguay S, Luz MA, Kassouf W, Aprikian AG. Relationship between initial PSA density with future PSA kinetics and repeat biopsies in men with prostate cancer on active surveillance. Prostate Cancer Prostatic Dis. 2011;14:53-7.

28. Stamey TA, McNeal JE, Yemoto CM, Sigal BM, Johnstone IM. Biological determinants of cancer progression in men with prostate cancer. JAMA. 1999:281:1395-400.

\section{Submit your next manuscript to BioMed Central and take full advantage of:}

- Convenient online submission

- Thorough peer review

- No space constraints or color figure charges

- Immediate publication on acceptance

- Inclusion in PubMed, CAS, Scopus and Google Scholar

- Research which is freely available for redistribution 